MaPan : Jurnal Matematika dan Pembelajaran

p-ISSN: 2354-6883 ; e-ISSN: 2581-172X

Volume 7 No 1, June 2019 (61--73)

DOI: https://doi.org/10.24252/mapan.2019v7n1a5

\title{
AKTIVITAS MATEMATIKA BERBASIS BUDAYA PADA MASYARAKAT PESISIR DI PASAR IKAN GEBANG KABUPATEN CIREBON
}

\author{
Herri Sulaiman \\ FKIP Universitas Swadaya Gunung Jati Cirebon \\ Jl. Perjuangan No.1 Cirebon, Jawa Barat \\ E-mail: herrimsc@gmail.com
}

Submitted: 05-04-2019, Revised: 30-05-2019, Accepted: 30-05-2019

\begin{abstract}
Abstrak:
Tujuan penelitian ini untuk mendeskripsikan aktivitas etnomatematika pada budaya lokal masyarakat pesisir di pasar ikan Gebang Kabupaten Cirebon. Penelitian ini merupakan jenis penelitian kualitatif. Pengambilan sampel dalam penelitian ini menggunakan teknik sampel dengan pertimbangan tertentu (purposive sampling), adapun sampelnya yaitu 2 tokoh adat, 3 pegawai pasar, 3 tokoh masyarakat, 3 nelayan, dan 2 pedagang ikan. Peneliti menggunakan tiga teknik pengumpulan data yaitu dengan metode observasi, wawancara, dan dokumentasi dengan menggunakan analisis domain. Adapun untuk memeriksa keabsahan data digunakan triangulasi sumber data. Hasil penelitian menunjukkan bahwa terdapat aktivitas matematika berbasis budaya di pasar ikan Gebang Cirebon. Hal ini dapat dilihat dari aktivitas menghitung, membilang, mengukur dan membuat rancang bangun.
\end{abstract}

Kata Kunci : Aktivitas, Etnomatematika, Budaya, Pesisir Gebang Cirebon

\section{MATHEMATICAL ACTIVITIES BASED ON CULTURE OF COASTAL COMMUNITIES IN PASAR IKAN GEBANG KAB. CIREBON}

\section{Abstract:}

The purpose of this study was to describe the ethnomatematic activities in the local culture of coastal communities in pasar ikan Gebang Cirebon. This research used qualitative approach. The samples were 2 traditional leaders, 3 market employees, 3 community leaders, 3 fishermen, and 2 fish traders who were choosed by using purposive sampling. The researcher used three data collection techniques, namely observation, interview, and documentation then data were analyzed using domain analysis. Triangulation of data sources was used to check the validity of the data. The results indicated that there were cultural-based mathematical activities in pasar ikan Gebang Cirebon which was showed by the activity of counting, measuring and making design.

Keywords: Activity, Ethnomatematics, Culture, Coastal Gebang Cirebon

How to cite: Sulaiman, H. (2019). Aktivitas matematika berbasis budaya pada masyarakat pesisir di pasar ikan Gebang Kabupaten Cirebon. MaPan : Jurnal Matematika dan Pembelajaran, 7(1), 61-73. 


\section{PENDAHULUAN}

Pengaruh modernisasi terhadap kehidupan berbudaya tidak dapat dihindari. Arus globalisasi saat ini yang berkembang dengan pesat dan dikenal dengan era industri 4.0 secara cepat ataupun lambat berdampak pada mengikisnya nilai-nilai budaya luhur yang dimiliki oleh bangsa dan negara kita. Hal ini terjadi karena kurangnya pengetahuan generasi muda akan pentingnya nilai budaya dalam masyarakat. Generasi muda saat ini cenderung acuh dan tidak peduli akan kelestarian budaya di sekitar lingkungannya karena fokus dengan teknologi modern yang berkembang pesat saat ini, sehingga akibat yang ditimbulkan ialah generasi muda tidak memiliki pengetahuan yang memadai dan acuh terhadap budayanya sendiri. Alfonsa (2016) mengatakan bahwa kemajuan suatu bangsa itu ketika warganya terutama generasi muda melestarikan dan menghargai budayanya sehingga tidak punah dan terus ada walaupun zaman terus berubah. Pendidikan dan budaya adalah sesuatu yang tidak dapat dihindari dalam aktivitas kehidupan masyarakat sehari-hari, karena budaya sebagai kesatuan utuh dan menyeluruh yang berlaku dalam suatu masyarakat, sedangkan pendidikan sebagai kebutuhan dasar untuk mengembangkan wawasan keilmuan bagi setiap individu dalam masyarakat. Budaya sebagai keseluruhan sistem gagasan, tindakan, dan hasil karya manusia pada kehidupan bermasyarakat yang mana proses untuk memilikinya diperlukan kegiatan belajar secara berkala. Dengan kata lain seluruh aktivitas manusia merupakan budaya atau kebudayaan karena tidak ada tindakan manusia di kehidupan bermasyarakat yang tidak memerlukan proses belajar dalam mengerjakan sesuatu dengan keterampilan yang dimiliki.

Dalam pergaulan masyarakat modern sekarang ini, dapat diakui bahwa matematika sebagai salah satu mata pelajaran yang penting di sekolah formal. Akan tetapi, mengajar matematika dan mentransfer pengetahuan kepada peserta didik dengan optimal merupakan suatu hal yang sulit untuk dilakukan (Gazali, 2016). Pemberlakuan kurikulum 2013 edisi revisi sebagai reformasi simbolis dalam pendidikan matematika di Indonesia untuk saat ini ternyata banyak memberikan tuntutan belajar yang cukup berat bagi peserta didik. Konsep-konsep matematika yang ada di dalamnya beraneka ragam hingga mencapai tingkatan High Ordering Thinking and Skills (HOTS) dan peserta didik cukup merasa kesulitan dalam memahami dan menggunakan daya nalar ketika menguasai konsep-konsep matematis. Salah satu cara untuk mengembangkan daya nalar peserta didik melalui pembelajaran matematika berbasis budaya yang dikenal dengan istilah etnomatematika. Menurut Risdiyanti (2017), 
etnomatematika sebagai penghubung antara matematika dengan budaya lokal ketika beraktivitas sehari-hari dan menurut (Supriadi, Srisetyawan, \& Tiurlina, 2016), mengemukakan bahwa matematika memiliki nilai-nilai sosial dan terikat dengan budaya setempat. Hal ini menjadi suatu celah bagi kalangan pendidik yang memanfaatkan etnomatematika sebagai pendekatan pembelajaran di sekolah sehingga matematika sebagai pelajaran yang mudah dan menyenangkan (Arindiono \& Ramaadhani, 2013). Konsep matematika yang dipelajari peserta didik dapat dikombinasikan dengan budaya lokal di sekitar lingkungannya (Maryati \& Prahmana, 2018) sehingga dapat mempelajari dari dua sisi yaitu budaya lokal dan konsep matematika.

Sejalan dengan pendapat Wahyuni (2013) yaitu etnomatematika mencakup ide-ide matematika, pemikiran dan praktik yang dikembangkan oleh semua budaya dalam kesatuan kehidupan yang dijalankan oleh masyarakat lokal secara turun temurun. Selain itu, etnomatematika juga dianggap sebagai program yang bertujuan untuk mempelajari bagaimana peserta didik memahami, mengelola, dan mengartikulasikan sehingga dapat menggunakan ide-ide matematika, konsep, dan praktik yang dapat memecahkan persoalan konteks matematis di sekolah maupun di lingkungan sekitar tempat tinggalnya. Indonesia memiliki beragam suku, budaya, ataupun produk yang dimiliki oleh setiap suku menandakan bahwa negeri ini kaya akan beraneka ragam aktivitas etnomatematika di dalamnya, tidak terkecuali adalah lingkungan pesisir pasar ikan nelayan Kecamatan Gebang Kabupaten Cirebon, yang diyakini memiliki aktivitas etnomatematika yang diterapkan masyarakat nelayan dalam menjalani roda kehidupannya sehari-hari.

Adapun aktivitas matematika untuk masyarakat nelayan di pasar ikan Gebang Kabupaten Cirebon yaitu menghitung, membilang, mengukur, mendesain konstruksi bangunan, dan penunjuk arah atau lokasi. Jadi, dari penjelasan yang telah dipaparkan, maka tujuan dari penelitian ini ialah untuk mengeksplorasi dan mengungkapkan seluruh aktivitas masyarakat nelayan sehari-hari dalam menjalankan roda kehidupan secara turun-temurun yang ada kaitannya dengan konsep matematis. Narasumber sebagai bahan untuk memperoleh data penelitian berasal dari beberapa tokoh masyarakat yang diambil secara acak dengan memperhatikan pekerjaan yang dilakukan seharihari, seperti nelayan, bakul, penjual ikan, pengepul ikan, tokoh adat, perangkat desa, dan lain sebagainya. Dengan demikian, data penelitian yang diperoleh benar-benar sesuai dan valid dengan keadaan yang sebenarnya. Penelitian ini merujuk pada beberapa penelitian sebelumnya. Abi (2016) dalam tulisannya 
membahas kemungkinan pengintegrasian etnomatematika ke dalam kurikulum matematiika dan model pembelajaran yang mendukung pembelajarannya. Model pembelajaran yang sesuai ialah Contextual Teaching and Learning (CTL). Selain itu, Wahyuni (2013) dalam tulisannya mengatakan bahwa berbagai bentuk kegiatan sehari-hari maupun ritual dari masyarakat pesisir selatan kecamatan Puger seperti jenis-jenis permainan yang dimainkan oleh anak-anak. Bentuk aktivitas masyarakat pesisir pantai selatan Kecamatan Puger bernuansa matematika yang bersifat operasi hitung dan telah berkembang dalam masyarakat seperti cara-cara menjumlah, mengurang, membilang, mengukur, menentukan lokasi, merancang bangun, dan bermain mempunyai nilai matematika yang terkait dengan konsep matematika.

Gagasan etnomatematika yang dipraktekkan dalam masyarakat Puger ini dapat memperkaya pengetahuan matematika yang telah ada. Dengan demikian posisi dari penelitian ini adalah sebagai rekomendasi perluasan kajian etnomatematika dari penelitian sebelumnya yang telah dijelaskan sebelumnya. Temuan dari penelitian ini yaitu memperluas konsep matematis dari aktivitas matematika di lingkungan pesisir pasar ikan gebang kabupaten Cirebon. Konsep matematis yang diperluas ialah materi sistem persamaan dua variabel yang diaplikasikan kepada kegiatan jual-beli nelayan dan bakul (pengepul). Selain itu, konsep aritmatika sosial juga dapat ditelaah lebih dalam dari kegiatan aktivitas nelayan di pesisir pantai.

\section{METODE PENELITIAN}

Pada penelitian ini, subjek ditujukan kepada masyarakat nelayan di pasar ikan Gebang kabupaten Cirebon. Adapun wawancara dilakukan kepada masyarakat yang tinggal di sekitar pasar ikan yang memiliki latar belakang pekerjaan berbeda-beda namun tinggal di wilayah yang sama. Subjek terdiri dari tiga orang nelayan (anak buah kapal), dua orang majikan (pemilik perahu), dua orang bakul (bos) rajungan dan ikan, dua orang buruh untuk membuat ikan asin dan menjemur teripang, tiga orang penjual ikan/hasil tangkapan nelayan, dua orang tukang pembuat perahu dan pemelihara perahu, satu orang tokoh adat (sesepuh desa Gebang dan berprofesi sebagai ahli hitungan kalender Jawa), dua orang perangkat desa beserta kepala desa Gebang. Teknik pengumpulan data dilakukan dengan wawancara, dokumentasi, dan observasi. Analisis data penelitian dilakukan melalui pendekatan kualitatif. Adapun data yang telah diperoleh berasal dari hasil wawancara, observasi, dan dokumentasi. Kemudian analisisnya dilakukan secara simultan dengan melakukan terlebih 
dahulu pemilahan data yang sejenis dan selanjutnya dilakukan reduksi data, penyajian data, penarikan kesimpulan, dan verifikasi. Data dikumpulkan berdasarkan beberapa kategori yakni aktivitas matematika untuk masyarakat nelayan di pasar ikan Gebang kabupaten Cirebon yaitu aktivitas menghitung dan membilang saat melakukan jual-beli bakul (tengkulak/pengepul) dengan nelayan yang baru datang dari laut dan pedagang dengan konsumen yang ingin membeli hasil laut secara eceran. Aktivitas mengukur berat dari hasil tangkapan ikan dari laut dengan menggunakan suatu wadah penyimpanan dan mengukur kapal atau perahu nelayan berbahan baku kayu. Lebih lanjut aktivitas berikutnya ialah mendesain konstruksi bangunan yang dalam hal ini ialah perahu atau kapal dengan jaring penangkap ikan, selain itu penunjuk arah atau lokasi juga sebagai aktivitas matematika dengan memperhatikan arah lokasi dengan peta menggunakan koordinat tertentu.

\section{HASIL PENELITIAN DAN PEMBAHASAN}

Nelayan adalah kelompok masyarakat yang aktivitas kehidupan seharihari tergantung pada hasil laut yaitu dengan melakukan penangkapan ikan. Mereka tinggal di wilayah pesisir dan memiliki peralatan penangkap ikan seperti perahu, kapal, jala, jaring pukat harimau, dan lain sebagainya. Wilayah pesisir pantai utara merupakan sumber daya potensial di wilayah Kabupaten Cirebon sebagai bagian dari provinsi Jawa Barat terletak di bagian timur yang berbatasan dengan Jawa Tengah, dengan hasil lautnya seperti udang rebon, ikan tuna, tenggiri, teripang, tongkol, rajungan, ikan teri, ikan asin, dan sebagainya. Daerah penghasil hasil laut di kabupaten Cirebon salah satunya ialah desa Gebang namun mayoritas masyarakat hidup di bawah garis kemiskinan. Kemiskinan dan masalah sosial ekonomi yang dialami oleh masyarakat nelayan pasar ikan Gebang berakar pada faktor-faktor kompleks yang saling berkaitan satu sama lainnya. Hal ini dikarenakan mayoritas untuk kategori sosial, nelayan Gebang adalah nelayan tradisional dan nelayan buruh. Mereka adalah penyumbang utama kuantitas produksi perikanan tangkap di wilayah Gebang dan sekitarnya. Walaupun demikian, kondisi kesejahteraan mereka dikatakan kurang karena akibat dari proses transaksi ekonomi yang timpang dan eksploitatif yang kurang adil. Dalam hal ini, nelayan tidak memperoleh bagian pendapatan yang besar. Pihak yang paling diuntungkan ialah pedagang ikan berskala besar atau pedagang perantara (bakul). Para bakul inilah yang sesungguhnya menjadi penguasa ekonomi di desa nelayan Gebang. Karakteristik nilai budaya bagi masyarakat nelayan di pasar ikan gebang 
dimulai dari upacara nadran yang berarti mensyukuri hasil tangkapan ikan, mengharap peningkatan hasil pada tahun mendatang dan berdoa agar tidak mendapat aral melintang dalam mencari nafkah di laut. Nadran ialah tradisi hasil akulturasi budaya Islam dan Hindu yang diwariskan sejak ratusan tahun secara turun-temurun. Kata nadran berasal dari kata nazar yang bermakna pemenuhan janji. Inti upacara nadran adalah mempersembahkan sesajen (yang merupakan ritual agama Hindu untuk menghormati roh leluhurnya) kepada penguasa laut agar diberi limpahan hasil laut, sekaligus ritual tolak bala (diberikan keselamatan). Sesajen yang diberikan disebut ancak berupa anjungan berbentuk replika perahu yang berisi kepala kerbau, kembang tujuh rupa, buah-buahan, makanan khas, dan lain sebagainya. Sebelum dilepaskan ke laut, ancak diarak terlebih dahulu mengelilingi tempat-tempat yang telah ditentukan sambil diiringi dengan berbagai suguhan seni tradisional, seperti tarling, genjring, barongsai, telik sandi, jangkungan ataupun seni kontemporer (drumband), dan secara rutin selalu digelar wayang kulit selama satu minggu. Nadran sering disebut labuh saji diartikan sebagai upacara pesta laut masyarakat nelayan sebagai perwujudan ungkapan syukur kepada Tuhan Yang Maha Esa atas rezeki yang diberikan-Nya lewat hasil laut yang selama ini didapat. Selain itu, dalam upacara nadran juga dilakukan permohonan agar diberi keselamatan dalam melaut, serta tangkapan hasil laut mereka berlimpah pada tahun mendatang.

Masyarakat nelayan pasar ikan Gebang Kabupaten Cirebon secara turun temurun melakukan aktivitas sehari-hari dalam mencari nafkah melalui pengolahan hasil laut. Namun, secara sadar atau tidak, mereka telah melakukan aktivitas yang ada kaitannya dengan konsep-konsep matematis. Mereka melakukan aktivitas sehari-hari berdasarkan apa yang mereka pelajari dari orang tua terdahulu dan kini diterapkan ketika sudah cukup umur untuk beraktivitas. Kemudian mereka pun kembali mengajarkan kepada anakanaknya. Berikut ini dibahas aktivitas matematika yang terdapat di lingkungan masyarakat nelayan pasar ikan Gebang Kabupaten Cirebon.

Masyarakat nelayan pasar ikan Gebang Kabupaten Cirebon dalam penyebutan bilangan menggunakan istilah yang berbeda dengan masyarakat lainnya, karena telah menggunakan satuan lokal. Masyarakat ini berasal dari penggabungan dua suku yaitu Jawa pesisir dan Sunda sehingga dalam membilang dan menghitung dari pola bilangan tersebut menjadi berbeda. Aktivitas menghitung dapat dijumpai dari praktik jual beli ikan antara bakul dan nelayan. Aktivitas menghitung yang ditemukan ialah menentukan harga 
jual, harga beli, laba, dan rugi. Selain itu, aktivitas membilang juga sering dijumpai pada masyarakat tersebut. Hal ini ditemukan pada saat bakul membeli hasil tangkapan ikan kepada nelayan. Lebih jelasnya berikut ini diberikan tabel yang menggunakan istilah lokal dalam aktivitas membilang.

Tabel 1. Daftar Istilah lokal dan Satuan dalam Matematika

\begin{tabular}{|c|c|c|c|}
\hline No. & Nama Istilah Lokal & Pengertian & $\begin{array}{c}\text { Satuan dalam } \\
\text { matematika }\end{array}$ \\
\hline 1. & Eblek & $\begin{array}{l}\text { Wadah untuk menjemur } \\
\text { ikan teri berbentuk persegi } \\
\text { panjang terbuat dari kayu. }\end{array}$ & $\begin{array}{lll}\begin{array}{l}\text { Maksimal } \\
(\mathrm{kg})\end{array} & 2 & \text { kilogram } \\
& & \\
\end{array}$ \\
\hline 2. & Termos & $\begin{array}{l}\text { Satuan ukuran yang } \\
\text { menyatakan bobot } \\
\text { berat khusus untuk } \\
\text { cerebung. }\end{array}$ & $\begin{array}{l}\text { Maksimal } 18 \text { kilogram } \\
(\mathrm{kg})\end{array}$ \\
\hline 3. & Ember Tang & $\begin{array}{l}\text { Satuan ukuran yang } \\
\text { menyatakan bobot suatu } \\
\text { berat khusus untuk hasil } \\
\text { laut seperti: ikan kembung, } \\
\text { lajan kecil, unger dan lain } \\
\text { sebagainya. }\end{array}$ & $\begin{array}{lll}\text { Maksimal } & 15 & \text { kilogram } \\
(\mathrm{kg}) & & \\
\end{array}$ \\
\hline 4. & Tiber & $\begin{array}{lr}\text { Satuan ukuran yang } \\
\text { menyatakan bobot suatu } \\
\text { berat khusus untuk } \\
\text { rajungan, ikan loang, tenggiri, } \\
\text { tongkol. }\end{array}$ & $\begin{array}{l}1 \text { kwintal untuk rajungan } \\
\text { Sedangkan untuk ikan } \\
\text { Loang, Tenggiri, Tongkol } \\
\text { daya maksimal hingga } \\
70 \mathrm{~kg} \text {. }\end{array}$ \\
\hline 5. & Geblong & $\begin{array}{l}\text { Wadah penyimpanan ikan } \\
\text { petek. }\end{array}$ & $\begin{array}{l}\text { Daya tampung maksimal } \\
2 \text { kilogram (kg). }\end{array}$ \\
\hline 6. & Boks & $\begin{array}{l}\text { Wadah penyimpanan ikan } \\
\text { petek berukuran jumbo. }\end{array}$ & $\begin{array}{l}\text { maksimal mencapai } \\
\text { bobot } 3 \text { kwintal }\end{array}$ \\
\hline 7. & Peti & $\begin{array}{l}\text { Wadah penyimpanan ikan } \\
\text { pari. }\end{array}$ & $\begin{array}{lll}\text { Mencapai maksimal } & 7 \\
\text { ton. } & & \end{array}$ \\
\hline 8. & Basket & $\begin{array}{l}\text { Satuan ukuran yang } \\
\text { menyatakan bobot suatu } \\
\text { berat khusus untuk ikan } \\
\text { bandeng, pari, sembilang, } \\
\text { pirik, teri, udang pecin, dan } \\
\text { udang krowe (berukuran } \\
\text { kecil). Selian itu ikan } \\
\text { sembilang dan ikan tongkol. }\end{array}$ & $\begin{array}{l}\text { Mencapai maksimal } 50 \\
\text { kg. Khusus untuk ikan } \\
\text { bandeng, pari, sembilang, } \\
\text { pirik, teri, udang pecin, dan } \\
\text { udang krowe (berukuran } \\
\text { kecil). Daya maksimal } \\
\text { bobot khusus untuk ikan } \\
\text { sembilang berukuran } \\
\text { sedang } 40 \mathrm{~kg} \text { dan ikan } \\
\text { tongkol berukuran } \\
\text { sedang } 60 \mathrm{~kg} \text {. }\end{array}$ \\
\hline
\end{tabular}


Berikut ini dipaparkan aktivitas menghitung dan membilang yang dilakukan oleh masyarakat nelayan dalam bentuk tabel di bawah ini.

Tabel 2. Contoh Aktivitas Menghitung dan Membilang di Pasar Ikan Gebang Kabupaten Cirebon

\section{Contoh aktivitas:}

Pada hari Kamis pukul 14.15 WIB, Ibu Hj. Ema membeli hasil laut kepada nelayan yang baru saja tiba dari melaut dengan rincian sebagai berikut

1. Dua buah geblong berisi ikan patek

2. 1,5 buah ember tang berisi ikan kembung

3. Tiga buah basket masingmasing berisi ikan tongkol, ikan bandeng dan ikan patek.

Untuk menghitung harga yang harus dibayarkan oleh ibu $\mathrm{Hj}$. Ema kepada nelayan dapat dilakukan sebagai berikut.

- Dua buah geblong berarti: $2 \times 2=4 \mathrm{~kg}$ dengan @1 kg ikan patek $=$ Rp10.000,00. Sehingga total harga untuk dua buah geblong adalah $\operatorname{Rp} 10.000,00 \times 4=$ Rp40.000,00.

- Satu koma lima ember tang berarti : $15 \mathrm{~kg}+7,5 \mathrm{~kg}=$ 22,5 kg ikan kembung dengan harga@1 kg ikan kembung Rp. 12.500,00. Sehingga total harga untuk 1,5 ember tang ialah Rp12.500,00 × 22,5 = Rp281.250,00

- Tiga buah basket untuk masing-masing ikan tongkol $60 \mathrm{~kg}$, ikan bandeng $50 \mathrm{~kg}$ dan ikan patek $60 \mathrm{~kg}$ dengan @1 kg ikan tongkol Rp12.000,00, @ 1 kg ikan bandeng Rp10.000,00 dan @

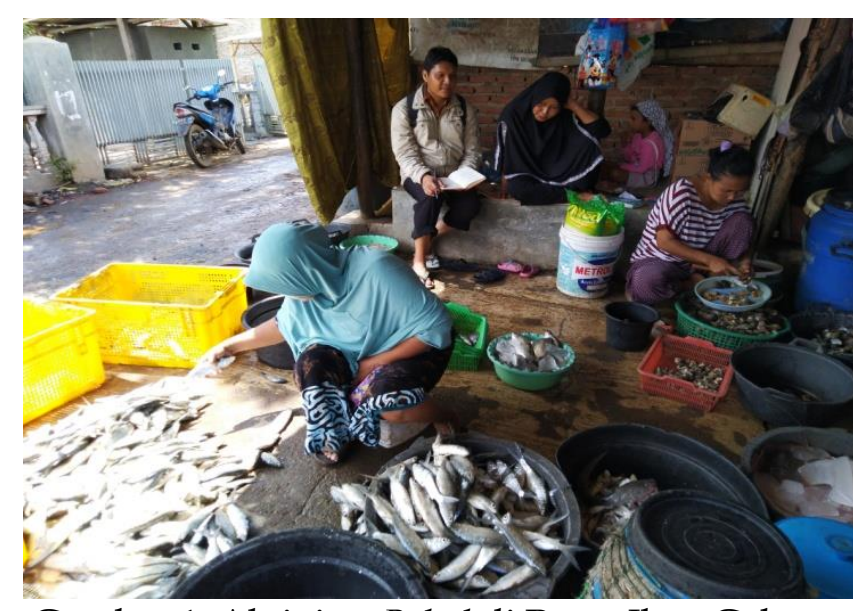

Gambar 1. Aktivitas Bakul di Pasar Ikan Gebang

(1)

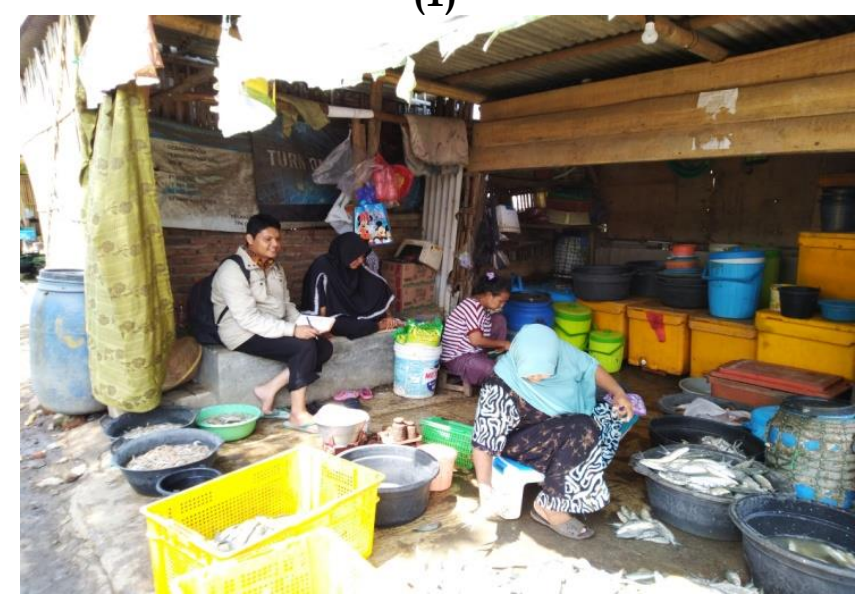

(2)

68| Volume 7, No 1, June 2019 
1 kg ikan patek Rp10.000,00.

Jadi, total yang harus

dibayarkan ialah

Rp12.000,00 × $60=$

Rp720.000,00, Rp10.000,00

x $50=\operatorname{Rp} 500.000,00$, dan

$\operatorname{Rp} 10.000,00 \times 60=$

Rp600.000,00.

Rp720.000,00 +

Rp500.000,00 +

Rp600.000,00 =

Rp1.820.000,00.

Dengan demikian total yang

harus dibayar ibu $\mathrm{Hj}$. Ema

kepada nelayan ialah

$\mathrm{Rp} 40.000,00+\mathrm{Rp} 281.250,00+$

Rp1.820.000,00 = Rp2.141.250,-.

Kemudian ibu Hj. Ema kembali menjual hasil pembelian dari nelayan kepada pedagang eceran di pasar ikan Gebang dengan rincian sebagai berikut.

- @ ikan patek $=\mathrm{Rp} 12.000,00 / \mathrm{kg} \times 4=\mathrm{Rp} 48.000,00$.

- @ ikan kembung Rp15.000,00/ kg x 22,5=Rp337.500,00

- @ ikan tongkol Rp18.000,00/ kg × $60=\mathrm{Rp} 1.080 .000,00$

- @ ikan bandeng Rp15.000,00/ kg x $50=$ Rp750.000,00

- @ ikan patek Rp13.000,00/kg x $60=\mathrm{Rp} 780.000,00$.

Maka jumlah total harga penjualan ialah Rp48.000,00 + Rp337.500,00 + $R p 1.080 .000,00+R p 750.000,00+R p 780.000,00=R p 2.995 .500,00$.

Sehingga keuntungan yang diperoleh ibu $\mathrm{Hj}$. Ema ialah: laba = harga penjualanmodal awal. Jadi laba yang diperoleh ibu Hj. Ema adalah $=$ Rp2.995.500,00 Rp2.141.250,00 = Rp854.250,00

\section{Kasus aktivitas masyarakat Penyelesaian kasus:}

\section{nelayan:}

Pada hari Jumat pukul 14.30 WIB, beberapa kapal nelayan di pasar ikan Gebang tiba dan berlabuh di pangkalan kapal. Nelayan pertama menjual hasil tangkapannya kepada bakul yaitu ibu Hj. Ema. Rencananya ingin membeli semua hasil tangkapan nelayan pada sore itu untuk kembali dijual keesokan harinya. Ibu Hj. Ema membeli hasil tangkapan ikan untuk beberapa nelayan dengan rincian sebagai berikut
Dari kasus ini dapat diubah ke dalam model matematika dan dapat diselesaikan dengan konsep eliminasi dan substitusi untuk sistem persamaan linear dua variabel.

Misalkan : banyaknya termos $=x$

Banyaknya basket $=\mathrm{y}$.

Jadi, diperoleh: $2 x+5 y=$ Rp378.000,00+ Rp825.000,00 maka :

$2 x+5 y=R p 1.203 .000,00$ (untuk nelayan pertama)

$x+3 y=R p 189.000,00+R p 721.800,00$ maka:

$x+3 y=R p 910.800,00$. (untuk nelayan kedua).

Sehingga sistem persamaan linearnya adalah :

$2 x+5 y=R p 1.203 .000,00$

$x+3 y=R p \quad 910.800,00$ : 
- Nelayan pertama, ibu Hj. Dari sistem di atas, dengan menyelesaikannya Ema membeli dua termos berisi udang cerebung sebanyak $10 \mathrm{~kg}$ seharga Rp378.000,00. Kemudian membeli lima basket berisi ikan tongkol berukuran sedang sedang seharga Rp.825.000,00.

- Nelayan kedua, ibu Hj Ema membeli satu termos berisi ikan lajan kecil yang mana volumenya sama dengan udang cerebung seperti pada nelayan 1 seharga Rp189.000,00. Kemudian membeli 3 basket berisi ikan deles berukuran sedang yang volumenya sama dengan ikan kembung seharga Rp721.800,00.

Pada kasus tersebut, yang ditanyakan adalah harga tiap kilogramnya apabila satuan matematika dikonversikan sama dengan ukuran hasil tangkapan laut dari kedua nelayan tersebut.

Dari tabel tersebut dapat diketahui bahwa aktivitas masyarakat nelayan di pasar ikan Gebang Kabupaten Cirebon memiliki konsep matematis dalam menjalankan roda kehidupan sehari-hari. Disadari atau tidak mereka telah melakukan aktivitas sehari-hari dalam mencari nafkah keluarga yang ternyata berkaitan dengan konsep matematis. Seperti contoh yang telah dijelaskan sebelumnya bahwa ibu $\mathrm{Hj}$. Ema sebagai bakul ikan membeli hasil tangkapan laut dari nelayan yang baru saja tiba. Kemudian beliau kembali menjual hasil pembeliannya kepada pedagang ikan di sekitar pasar ikan Gebang. Hal ini sesuai dengan konsep matematika untuk jenjang SMP yang mana materi yang dipelajari ialah konsep aritmatika sosial seperti mencari untung, rugi, modal, harga jual, persen untung, dan persen rugi. Selain itu, konsep sistem persamaan linear dua variabel (SPLDV) juga dapat diaplikasikan ke dalam etnomatematika ini yang mana mencari penyelesaiannya dilakukan dengan metode eliminasi 
dan substitusi. Berikut ini diberikan diagram alir yang menyatakan etnomatematika terhadap aktivitas masyarakat nelayan pesisir di pasar ikan Gebang Kabupaten Cirebon yang dapat dikaitkan ke dalam konsep matematis sebagai bahan pembelajaran matematika di SMP dengan aktivitas membilang dan menghitung.

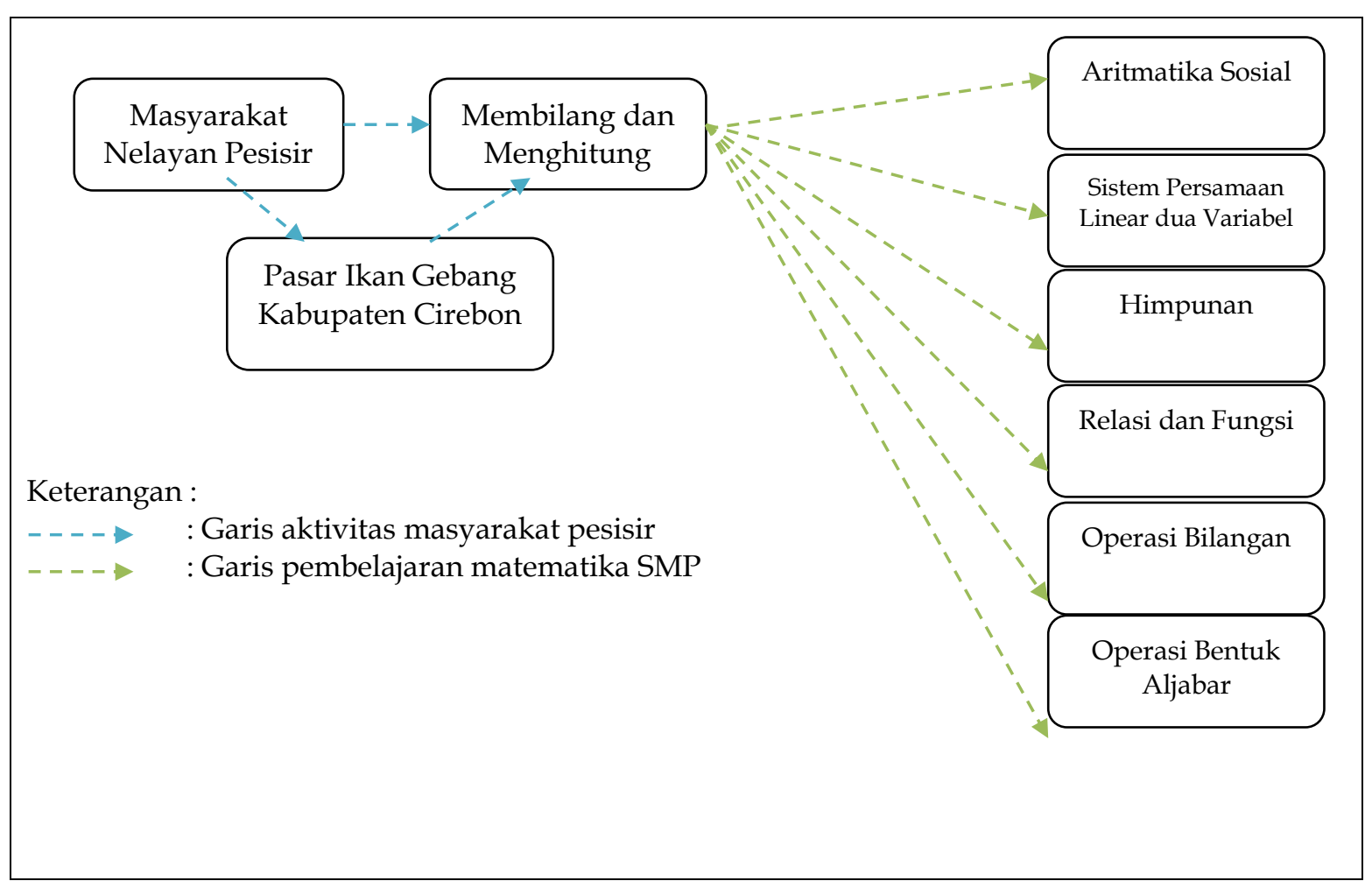

Gambar 2. Bagan Aktivitas Masyarakat Nelayan di Pasar Ikan Gebang Cirebon Terhadap Konsep Pembelajaran Matematika Jenjang SMP

Dari gambar tersebut, dapat diketahui bahwa aktivitas masyarakat pesisir nelayan di pasar ikan Gebang Kabupaten Cirebon dapat diterapkan ke dalam bahan pembelajaran matematika untuk jenjang SMP. Hal ini dapat dilihat dari konsep-konsep matematika SMP yang dapat dikaitkan dengan materi matematika yang dimulai dari aritmatika sosial, sistem persamaan linear dua variabel (SPLDV), teori himpunan, relasi dan fungsi, operasi bilangan, dan operasi pada bentuk aljabar. Sehingga sesuai dengan Muhtadi (2017) mengatakan bahwa matematika merupakan suatu bentuk budaya yang terintegrasi pada seluruh aspek kehidupan masyarakat di mana pun berada. Hal ini memungkinkan adanya konsep-konsep matematika tertanam di dalam praktik budaya dan mengakui bahwa semua orang mengembangkan cara khusus dalam melakukan aktivitas matematika yang disebut etnomatematika. 
Etnomatematika ini dapat pula diaplikasikan ke dalam pembelajaran di sekolah. Adapun produk yang dihasilkan nantinya berupa bahan ajar yang mengenalkan peserta didik akan konsep matematika sekaligus mengingat budaya yang berada di sekitar lingkungannya. Sejalan dengan pendapat Khairadiningsih (2015) yang mengatakan bahwa salah satu tujuan belajar matematika adalah membentuk skema baru dalam struktur kognitif dengan mempertimbangkan skema yang telah ada di dalam diri peserta didik sehingga terjadi asimilasi. Salah satu alternatifnya ialah mengaitkan antara pengetahuan yang telah dimiliki peserta didik dengan pemahaman pada situasi di lingkungannya. Oleh karena itu, dalam pembelajaran matematika perlu diawali dengan penggalian pengetahuan informal yang telah diserap peserta didik dari kehidupan dan kebudayaan masyarakat di sekitar tempat tinggalnya.

\section{SIMPULAN}

Berdasarkan hasil penelitian dan pembahasan yang telah dipaparkan sebelumnya, dapat dibuat kesimpulan berikut ini: (a) berbagai bentuk kegiatan baik kegiatan sehari-hari maupun kegiatan ritual masyarakat pesisir nelayan di pasar ikan Kabupaten Cirebon mempunyai nilai etnomatematika. Gagasan etnomatematika yang dipraktikkan dalam masyarakat tersebut dapat memperkaya pengetahuan matematika yang telah ada dan dapat dijadikan bahan ajar untuk pembelajaran matematika di jenjang SMP, (b) bentuk aktivitas masyarakat pesisir pantai nelayan di pasar ikan Kabupaten Cirebon bernuansa matematika yang bersifat operasi hitung telah dipraktikkan dan berkembang di masyarakatnya seperti cara untuk menjumlah, mengurang, membilang, dan menghitung yang terkait dengan konsep matematika, (c) beberapa potensi dari etnomatematika di masyarakat nelayan di pasar ikan kabupaten Cirebon sebagai local knowledge memberikan kontribusi dalam pemahaman konsep matematika di sekolah, khususnya jenjang SMP.

\section{DAFTAR PUSTAKA}

Abi, A. (2016). Integrasi etnomatematika dalam kurikulum matematika sekolah. Jurnal Pendidikan Matematika Indonesia, 1(1), 1-6. Retrieved from https://www.researchgate.net/publication/320277156_Integrasi_Etno matematika_Dalam_Kurikulum_Matematika_Sekolah

Alfonsa, A. A. (2016). Integrasi etnomatematika dalam kurikulum matematika sekolah. Jurnal Pendidikan Matematika Indonesia, 1(1), 1-6. Retrieved from http://journal.stkipsingkawang.ac.id/index.php/JPMI/article/view/7 5 
Arindiono, R. Y., \& Ramaadhani, N. (2013). Perancangan media pembelajaran interaktif matematika untuk siswa kelas 5 SD Rudi. Jurnal Sains Dan Seni Pomits, 2(1), 28-32.

Gazali, R. (2016). Pembelajaran yang bermakna. Jurnal Nasional Pendidikan Matematika Math Didactic, 2(3), 181-190. Retrieved from https://media.neliti.com/media/publications/176892-IDpembelajaran-matematika-yang-bermakna.pdf

Khairadiningsih, R. (2015). Eksplorasi Etnomatematika masyarakat suku Madura di Situbondo. Tesis Pendidikan Matematika Universitas Jember, 2(1). Retrieved from http://repository.unej.ac.id/handle/123456789/66826

Maryati \& Prahmana, R. C. I. (2018). Ethnomathematics: Exploring the activities of designing kebaya kartini. MaPan : Jurnal Matematika dan Pembelajaran, 6(1), 11-19.

Muhtadi, D. (2017). Sundanese ethnomathematics: Mathematical activities in estimating, measuring, and making patterns. Journal on Mathematics Education, 8(2), 185-198. Retrieved from https:// ejournal.unsri.ac.id/index.php/jme/article/view/ 4055

Risdiyanti, I. (2017). Ethnomatematics: Exploration in Javanese Culture. Journal of Physics, 37(1), 943-958. Retrieved from https://iopscience.iop.org/article/10.1088/1742-6596/943/1/012032

Supriadi, Srisetyawan, A., \& Tiurlina. (2016). Mengintegrasikan pembelajaran matematika berbasis budaya banten pada pendirian sd laboratorium UPI kampus Serang. Mimbar Sekolah Dasar, 3(1), 1-18. https:// doi.org/10.17509/mimbar-sd.v3i1.2510

Wahyuni, A. (2013). Peran etnomatematika dalam membangun karakter bangsa. Prosiding Seminar Nasional Matematika Dan Pendidikan Matematika FIMPA UNY, 9(4), 113-118. Retrieved from http://eprints.uny.ac.id/10738/1/P - 15.pdf 